\title{
SIM[PLY]: RAPID STRUCTURAL ASSEMBLIES USING CNC-FABRICATED PLYWOOD COMPONENTS
}

\author{
D. ALBRIGHT, V. BLOUIN, D.N. HARDING, U. HEINE \& D. PASTRE \\ Clemson University School of Architecture, Clemson, SC, USA.
}

\begin{abstract}
The Sim[PLY] framing system leverages CNC prefabrication and unique connection design in service of rapid and safe on-site assembly without power tools or heavy equipment. Sim[PLY] components are cut from standard sheets of structural plywood and interlock using tab and slot connections in lieu of nails. Steel cable ties are used to secure the connections. In addition to fast and accurate assembly, $\mathrm{CNC}$ processing also allows for various forms of intelligent customization, including mechanical and electrical systems integration, component labeling, and diminished thermal bridging.

Preliminary structural testing examined the performance of individual connections as well as the performance of full-scale assemblies, including rafters and shear walls. Test results confirmed the adequacy of the Sim[PLY] system for natural hazard loading scenarios, including seismic and hurricane events.

This paper describes the development and details of the Sim[PLY] system as well as preliminary testing and case studies from various applications. The reader will, in turn, recognize an accessible and economical framing system that simultaneously offers high quality control, minimal waste, structural resiliency, and rapid and intuitive assembly and disassembly.
\end{abstract}

Keywords: CNC, plywood, prefabrication, rapid assembly, sim[PLY].

\section{INTRODUCTION}

The Sim[PLY] framing system was developed under specific yet broadly-applicable constraints. The premise of the system is to leverage "high-tech" prefabrication techniques on the front-end in order to enable "low-tech" rapid assembly methods on the back-end. This premise has many other consequential benefits, not the least of which is that it relegates the time-consuming and skilled process of measuring and cutting framing members to the controlled environment of a fabrication shop, thereby enabling fast, safe, and unskilled on-site assembly. The unique CNC tab and slot connection design, which replaces nails as the responsible shear elements in the frame, makes the structure incredibly resilient and strong, and further capable of rapid, non-destructive disassembly. Furthermore, since all framing members are cut from standard sheets of structural plywood, it can be efficiently flat-packed for transportation to and from the site.

Sim[PLY] represents a critical departure in the context of rapid assemblies. In the vein of Botha and Sass' Instant House and others such as WikiHouse and Facit Homes, Sim[PLY] is positioned as an evolutionary step beyond traditional light wood framing and draws upon the near universal familiarity with this system [1-3]. Using conventional materials, Sim[PLY] strives first for safety, speed, and affordability in the construction of permanent and durable structures. The frame geometry and joinery is a consequence of these principal goals, not the reverse, which translates into a truly democratic and accessible building system.

\section{TENETS}

Sim[PLY] is intended to occupy a gap between traditional inline lightwood framing and modular prefabricated construction. As a precursor to its development, the team identified faults at the opposing ends of this spectrum. On the one hand, traditional inline 
lightwood framing is supremely economical, but requires skilled workers using loud, dangerous tools, and creates an uncontrolled on-site waste stream. On the other hand, modular prefabricated construction provides excellent waste management, high precision, and relegates loud, dangerous tools to a shop environment. However, the trade-offs include the necessity of transporting large, prefabricated building sections to site and using heavy equipment to place them, causing frequent, insensitive disturbances to the surroundings. Moreover, in both of these cases (traditional site-built and off-site prefab), the minimal sectional depth of the light wood frame and frequency of framing members does not allow for adequate insulation and promotes thermal bridging. Furthermore, neither of these systems was designed for rapid, unskilled assembly and neither provides for non-destructive disassembly.

By beginning with the goal of providing rapid, manual assembly that is intuitive and accessible, Sim[PLY] solves these shortcomings by combining the economy of traditional inline wood framing with the precision of modular prefabricated construction. Instead of a competitor to current techniques, Sim[PLY] is a logical evolution of the light wood frame. Its value and effectiveness are equally a result of its familiarity and its innovation.

\section{TECHNICAL}

The framing components of the Sim[PLY] system are cut from common $4 \mathrm{ft} \times 8 \mathrm{ft}(1.22 \mathrm{~m} \times$ $2.44 \mathrm{~m})$ sheets of $3 / 4$ "'-thick $(1.91 \mathrm{~cm})$ plywood sheathing, a highly-standardized industrial product with engineered physical properties. With respect to traditional graded lumber, plywood can offer enhanced dimensional stability because of the alternating grain direction of its layers. Wood tends to shrink or swell primarily in its radial and tangential grain directions, while it is stable in its longitudinal direction. The alternating grain direction in plywood serves to balance and minimize shrinkage, swelling, and warping. Structural plywood is also inherently devoid of the knots and other inconsistencies that can adversely affect dimension lumber. As opposed to dimension lumber, plywood also provides the opportunity to create substantial cavity depth in the structure to accommodate greater amounts of insulation. The Sim[PLY] system, as tested, allows for up to 12 inches $(30.48 \mathrm{~cm})$ of insulation and uses precut cellulose batts that fit neatly into the frame cavity.

When using plywood, it is critical that any mechanical fasteners pass through the face of the plywood rather than the edge so as to avoid splitting. For this reason, the Sim[PLY] system utilizes plywood flanges on all studs, joists, and rafters. These flanges are oriented perpendicularly to the webs and allow for the reliable fastening of exterior sheathing and interior finish materials. Thus, all structural sheathing is fastened with screws through the plywood flanges rather than into the edges of plywood webs. Sim[PLY] flanges are pre-routed with slots to accept the pre-routed tabs of the Sim[PLY] webs. Shear forces are transferred from the sheathing to the flanges via the screws and from the flanges to the webs via the tab and slot joints. The flanges are prevented from withdrawing from the webs by steel cable ties that bind these elements together. The tab and slot is a standard detail in the Sim[PLY] frame and is used in all primary framing members, and also for aligning and installing the sheathing and subfloor to the frame.

The ease of the assembly process is a direct result of the connection geometry, itself developed under the constraints of manual human labor and rapid, safe assembly. The exterior walls of the Sim[PLY] frame are erected in a tilt-up fashion. Once the deck is complete and the subfloor is in place, the walls can be assembled on this surface. A Sim[PLY] wall consists 


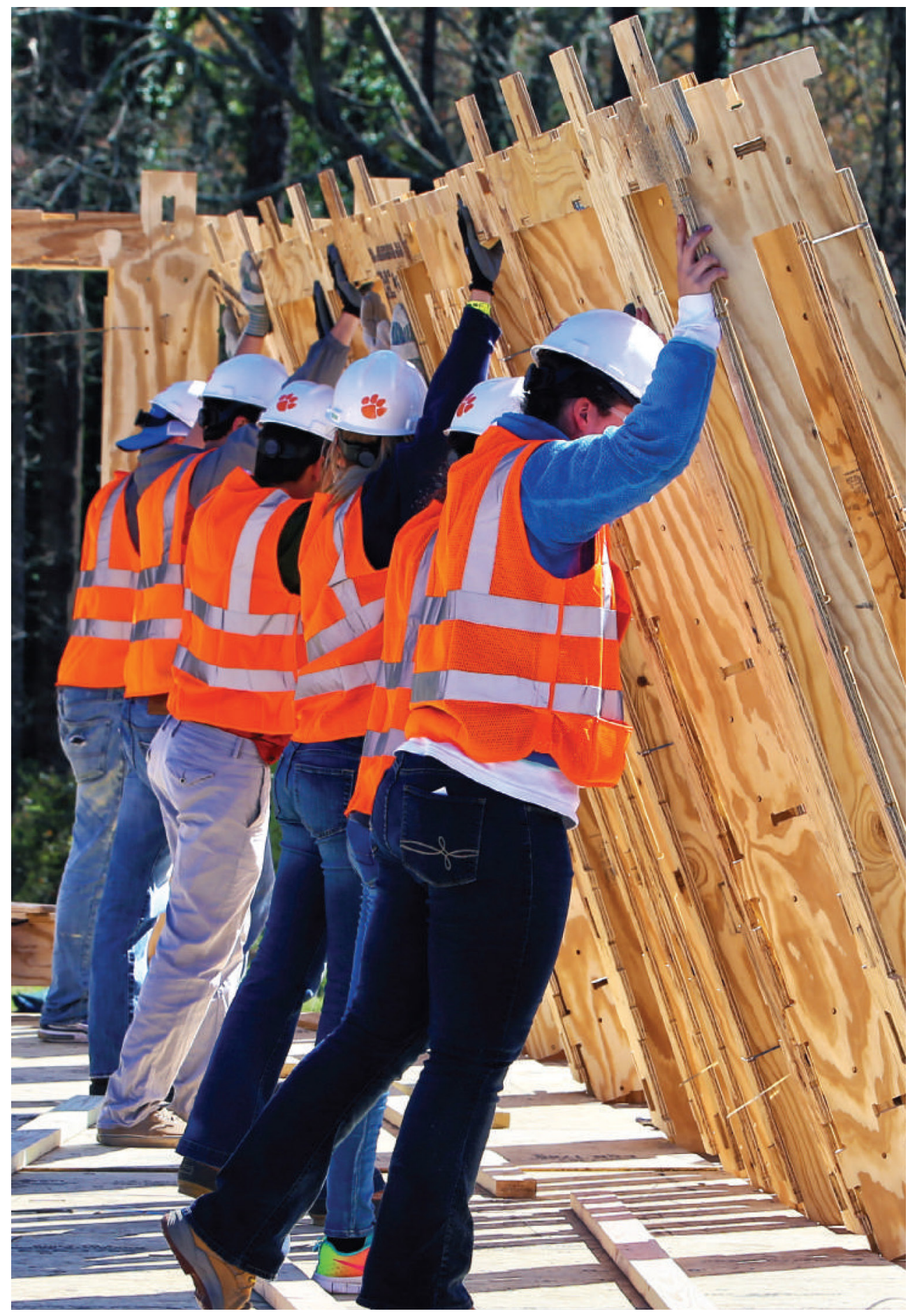


of a series of I-studs and Sim[PLY] connection elements at the base and top of the wall. Once assembled on the deck and joined with the cable ties, the wall is team-lifted into place. A curved joint guides the base of the wall into an upright position, and a ball joint on the face of the rim joist locates the wall in the vertical and horizontal planes. The wall is then malleted solidly into place and secured with additional cable ties.

The viability of the system was tested by its application to the 2015 Solar Decathlon Competition [4]. The efficacy of the Sim[PLY] connections, in particular, was demonstrated through laboratory testing that was reviewed by competition officials. Design loads were calculated in accordance with the procedures and practices of ASCE 7-10 [5]. The preliminary testing of the Sim[PLY] system could be divided into two categories. The first series of tests served to determine the capacity of discreet elements in the connections of the Sim[PLY] system. The second group of tests determined the capacities of full-scale wall and rafter assemblies. All tests were performed using 3/4" $(1.91 \mathrm{~cm}) 7$-ply Douglas Fir-Larch plywood. Conservative adjustment factors, consistent with those found in the National Design Specification for Wood Construction (NDS), were applied throughout the analysis of results [6].

Four single-fastener component tests were employed to evaluate the strength of the Sim[PLY] system's connections. These tests included a shear test of the tab and slot connection, a shear test of a screw connection in the plywood, a withdrawal test of a screw connecting sheathing to plywood, and a tensile test of the steel cable tie. Component tests followed all relevant ASTM standards [7]. The tests were performed on a $50 \mathrm{kN}$ (11.24 kips) universal testing machine following all procedures outlined in the standard.

The Solar Decathlon competition itself challenges student teams to build solar homes over a nine-day period. This proved to be an ideal scenario to demonstrate the effectiveness of the Sim[PLY] framing system in terms of constructability, speed, and safety. In total, the Sim[PLY] framing system has been implemented and field-tested in two houses for the Solar Decathlon competition. The first was a prototype built at Clemson University in Clemson, SC, USA. The second was built during the actual competition in Irvine, California, USA. The first demonstrated the effectiveness of the Sim[PLY] frame but also provided an opportunity to determine potential problems and make revisions before the constraints of the competition. This proved worthwhile, as the later house was ultimately completed successfully in the nine- day build period. The Sim[PLY] structural framing took only three shifts, or 1.5 days, to complete. This same frame was disassembled non-destructively in less than a single day.

\section{CONNECTIONS}

As discussed above, the Sim[PLY] framing system is composed of a number of unique connections, all of which are designed for rapid, manual assembly with simple hand tools. Detailed here are three of these connections as well as their role in the assembly of the structural frame.

\subsection{Tab and Slot}

The Sim[PLY] tab and slot is the most common connection in the frame and exists as a standard field connection (shown below), as well as a doubled configuration, a header configuration, and an edge configuration. The connection is created by routing a slot into one 


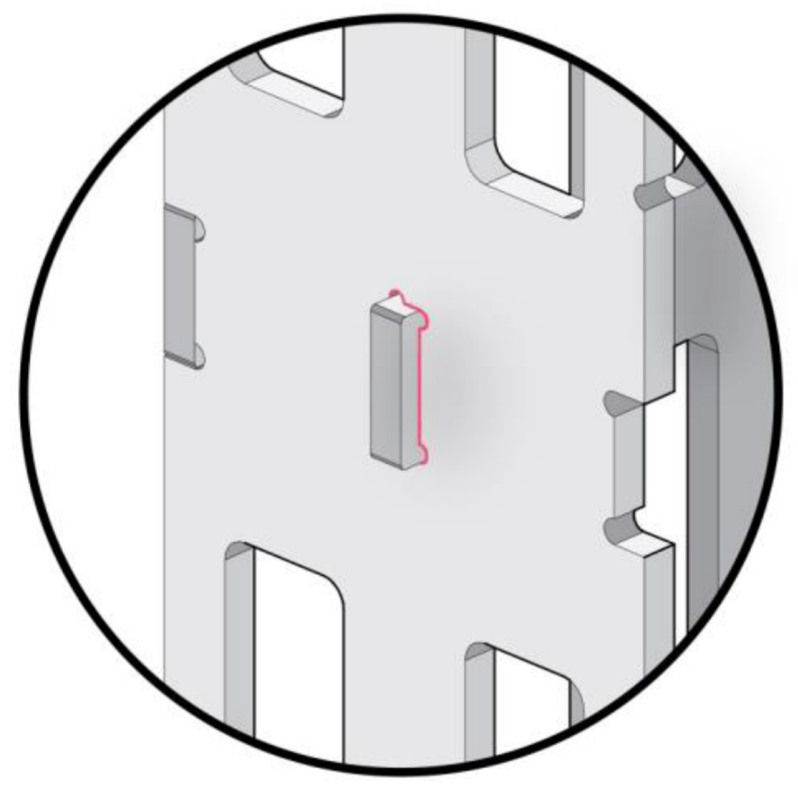

plywood member that then receives a tab that has been routed along the edge of the adjoining member. The tab and slot connection is common in CNC millwork, and is the pillar of the Sim[PLY] system, found in every primary structural component of the frame. It does the work of both locating the plywood components and handling shear forces. In order to prevent withdrawal, a steel cable tie is looped through pre-routed holes in the plywood members and around the connection, creating an overall joint that is notably strong in both shear and withdrawal.

While the tab and slot connection's primary application is at the web-to-flange joint of the Sim[PLY] I-stud, it can also be found in the roof rafters and floor joists in a structural capacity. It is also used to efficiently locate and install exterior sheathing and subflooring, where the sheets have been pre-routed with slots that coordinate with extended tabs on the frame.

\subsection{Ball joint}

The ball joint connection is found at the base of the exterior wall. When the wall, which is assembled on the floor deck, is then tilted up into place, the "ball" at the base of the exterior stud flanges nests into a corresponding void in the rim joist that is already in place. The connection is then secured with a steel cable tie. The ball joint serves to simultaneously locate the wall in the vertical plane, locate the wall horizontally along the platform, and also secure the wall to the platform and resist uplift.

Demonstrating the thoughtfulness of Sim[PLY]'s connection details, the ball joint connection has been designed with a void below the "ball" in the completed connection, as can be seen above. This void is sized to accept a pry bar that is used to easily and non-destructively reverse the connection and disassemble the frame. 


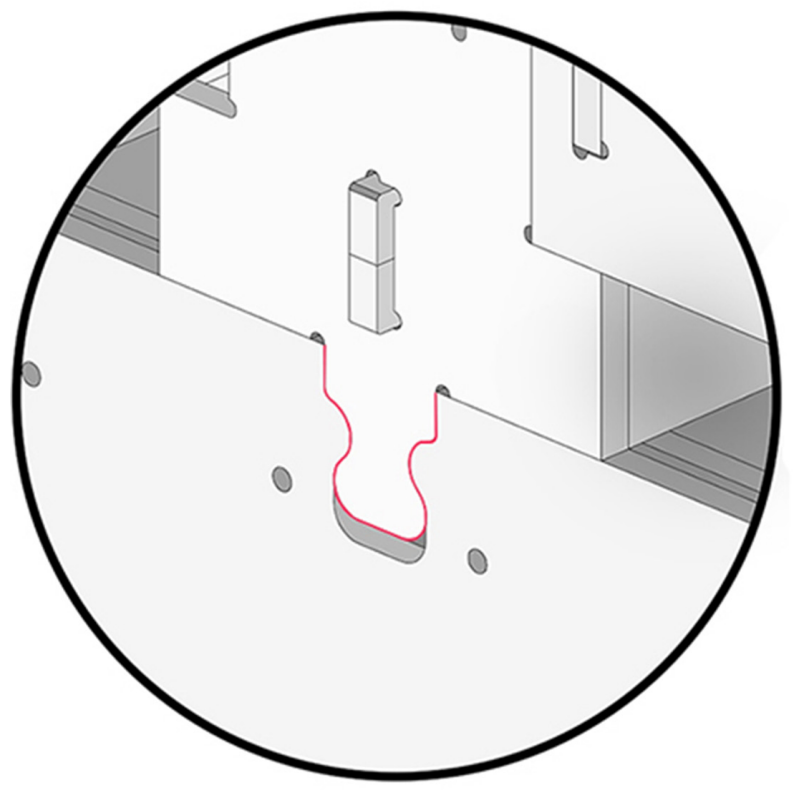

\subsection{Tilt-Up wall}

The tilt-up wall joint is used in conjunction with the ball joint above and further demonstrates the thoughtfulness of Sim[PLY]'s connections. The tilt-up wall joint consists of a curved protrusion at the base of the wall that corresponds with a curved relief cut in the floor joist below. This joint primarily aids in alignment while erecting the wall and helps to guide the ball joint into place in the rim joist on the opposite side.

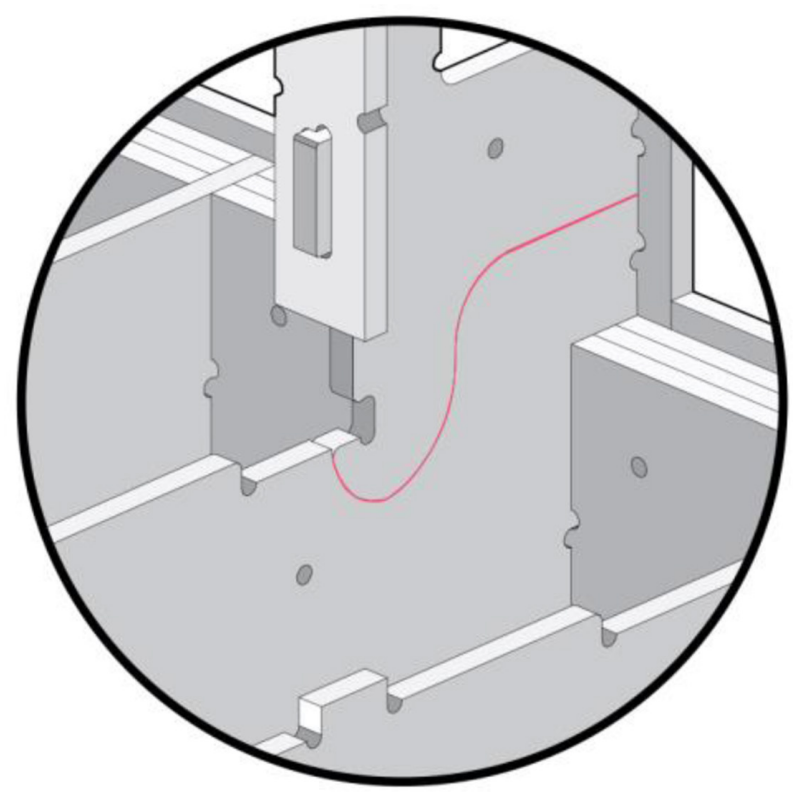




\section{CONCLUSION}

Outside of the Solar Decathlon projects, future applications for the Sim[PLY] framing system are being researched and tested in design studios at the Clemson University School of Architecture. These include a modular "tiny house" concept and various graduate studenthousing scenarios, as well as a deployable kitchen structure for aiding community farming programs. By applying the tenets of the Sim[PLY] system to different building types by way of its structural implementation, students are proving its comprehensive value. Because of the broad fundamental base on which the system is built, the potential future applications are many and diverse, both in the context of rapid assemblies and beyond.

\section{ACKNOWLEDGEMENTS}

The Solar Decathlon project referenced in this paper was funded in part by the Office of Energy Efficiency and Renewable Energy (EERE), U.S. Department of Energy, under Award Number DE-. EE0006559. The authors are also thankful for the facilities and technical support provided by students, faculty and staff in the Glenn Department of Civil Engineering at Clemson University, as well as Clemson's interdisciplinary Wood Utilization + Design Institute. We also thank graduate assistant William Slowik for his contributions in preparing this paper.

\section{REFERENCES}

[1] Botha, M. \& Sass, L., "Instant House: A model of design production with digital fabrication." International Journal of Architectural Computing, Vol. 4, No. 4 (2006), 109-123. https:/doi.org/10.1260/147807706779399015

[2] Parvin, A. \& Ierodiaconou, N., "WikiHouse," http://www.wikihouse.cc/WikiHouse_ Partners_2016_v1.7.1.pdf (accessed 11 November 2016).

[3] Facit Homes, http://facit-homes.com/made-with-intelligence/precision-manufacturing (accessed 11 November 2016).

[4] The Solar Decathlon competition is held biannually by the U.S. Department of Energy in conjunction with the National Renewable Energy Laboratory.

[5] American Society of Civil Engineers. ASCE/SEI 7-10 Minimum Design Loads for Buildings and Other Structures, 2013.

[6] American Wood Council. National Design Specification for Wood Construction, 2012.

[7] Component tests followed ASTM D1761-12 Standard Test Methods for Mechanical Fasteners in Wood. 